\section{Increasing incidence of IDDM a consequence of improved hygiene?}

Dear Sir,

Karvonen et al. [1] recently reviewed the wordwide incidence of IDDM and showed an increasing trend in a large number of countries and in all continents analysed. Simple explanations such as changes in ascertainment rates can be ruled out and environmental factors such as diet, in particular during early infancy, have been discussed [1]. An even more radical view regards IDDM as a "modern disease" that has become prominent only in the last two centuries [2].

We want to point out that beside diet, a major environmental factor controlling diabetes incidence may be the exposure to microbial antigens, postnatally and during early infancy. A major reduction in such exposure has occurred with the introduction of hygienic measures and is further decreasing with the ever growing hygienic awareness, with the use of disposables and of food industry products for baby care. Animal data indeed suggest that strict hygiene favours diabetes development if there is a genetic predisposition. Better hygiene with concomitant lower risk of infections increases the incidence of disease in genetically diabetes prone $B B$ rats and NOD mice $[3,4]$. The diabetes incidence in $\mathrm{BB}$ rats or NOD mice can be reduced to near zero if animals are exposed to high doses of bacterial antigens early in life $[5,6]$. Early contact with microbial antigens appears to modulate macrophage function [6] which is known to be abnormal in diabetes-prone animals $[7,8]$, with concomitant downregulation of cellular autoaggression against islet beta cells [9].

These animal data show that early contact with microbial antigens prevents autoimmune diabetes. Hygiene or its absence in early infancy thus should be regarded as a candidate environmental factor controlling the incidence of IDDM. Our suggestion does not ignore that genetics and probably diet are determinants of regional differences in diabetes incidence. The predicted relevance of postnatal hygiene may be best recognized by analysing changes of diabetes incidence over time within a given region in relation to indices of exposure of infants to microbial infections.

Yours sincerely,

H. Kolb and R.B. Elliott

\section{References}

1. Karvonen M, Tuomilehto J, Libman I, LaPorte R, for the World Health Organization DIAMOND Project Group (1993) A review of the recent epidemiological data on the worldwide incidence of Type 1 (insulin-dependent) diabetes mellitus. Diabetologia 36: 883-893

2. Bottazzo GF (1993) On the honey disease. A dialogue with Socrates. Diabetes 42: 778-800

Corresponding author: Prof. Dr. Hubert Kolb, Diabetes Research Institute, at the University of Düsseldorf, Auf'm Hennekamp 65, D-40225 Düsseldorf, Germany
3. Like AA, Guberski DL, Butler L (1991) Influence of environmental viral agents on frequency and tempo of diabetes mellitus in BB/Wor rats. Diabetes 40: 259-262

4. Wilberz S, Partke HJ, Dagnaes-Hansen F, Herberg L (1991) Persistent MHV (mouse hepatitis virus) infection reduces the incidence of diabetes mellitus in non-obese diabetic mice. Diabetologia 34:2-5

5. Sadelain MWJ, Qin HY, Sumoski W, Parfrey N, Singh B, Rabinovitch A (1990) Prevention of diabetes in the BB rat by early immunotherapy using Freund's Adjuvant. J Autoimmunity 3: $671-680$

6. Yagi J, Matsumoto M, Kishimoto Y, Makino S, Harada M (1991) Possible mechanism of the preventive effect of BCG against diabetes mellitus in NOD mice. Cell Immunol 138: 142-149

7. Serreze DV, Hamaguchi K, Leiter EH (1989) Immunostimulation circumvents diabetes in NOD/Lt mice. J Autoimmunity 2: 759-776

8. Rothe H, Fehsel K, Kolb H (1990) Tumour necrosis factor alpha production is upregulated in diabetes prone $\mathrm{BB}$ rats. Diabetologia 33: 573-575

9. Shehadeh NN, LaRosa F, Lafferty KJ (1993) Altered cytokine activity and adjuvant inhibition of autoimmune diabetes. $\mathrm{J}$ Autoimmunity 6:291-300

\section{Isolated hyperproinsulinaemia heralding diabetes mellitus?}

Dear Sir,

Normally proinsulin, the precursor of insulin, is only detected in the blood in small amounts $(<15 \mathrm{pmol} / \mathrm{l})$. We report here a case of isolated hyper-proinsulinaemia in a patient suspected to be suffering from insulinoma. A 40-year-old woman, who had not previously been hospitalized, was admitted because of attacks of profuse sweating and dizziness which occurred spontaneously or in connection with physical strain. During prolonged fasting (72 h) the blood glucose values were between 3.6 and $4.8 \mathrm{mmol} / \mathrm{l}$, but fasting proinsulin determined by ELIZA was $150 \mathrm{pmol} / 1$ $(<15 \mathrm{pmol} / \mathrm{l})$, whereas serum insulin and $\mathrm{C}$-peptide were within normal range $[1,2]$. During an oral glucose tolerance test blood glucose was as follows: $4.5,11.9,9.6 \mathrm{mmol} / \mathrm{l}$ at the start and after 60 and $120 \mathrm{~min}$, respectively.

Calculated by the formulae derived from the HOMAS method [3] the following values were obtained: \% beta-cell function $=78 \%$; insulin resistance $\mathrm{R}=1$. So neither the beta-cell function nor the insulin sensitivity was impaired. We suggest that IDDM (insulin-dependent diabetes mellitus) may develop in patients with hyperproinsulinaemia due to insufficient enzymatic cleavage of proinsulin to insulin.

Yours sincerely,

A. G. Jensen, D. Møller Jensen, R. Smith Pedersen, J. Kvetny

Corresponding author: Dr. A. G. Jensen, Department of Internal Medicine, Esbjerg County Hospital, DK-6700 Esbjerg, Denmark 